\title{
Arduino-based Digital Advanced Audiometer
}

\author{
Nur Hudha Wijaya ${ }^{1}$, Miftah Ibrahim², Nishith Shahu ${ }^{3}$, Mian Usman Sattar ${ }^{4}$ \\ ${ }^{1,2}$ Department of Electrical Engineering, Universitas Muhammadiyah Yogyakarta, Yogyakarta, Indonesia \\ ${ }^{3}$ Departement of Electrical Engineering, Gujarat Technological University, India \\ ${ }^{4}$ Information Systems, University of Management and Technology, Pakistan. \\ hudhapmy@gmail.com,miftah.ibrahim.2015@vokasi.umy.ac.id, nish2687@gmail.com,usman.sattar@umt.edu.pk
}

\begin{abstract}
The ear is an organ that is able to detect or recognize sound and also has a lot to play in the balance and position of the body. The ears are organs that are very vulnerable to noise. There are two common causes of hearing loss, namely decreased hearing conduction (hearing loss) and nerve hearing (sensorineural hearing loss). To prevent deafness, hearing control is necessary. Generally to test hearing function is done regularly by the ENT doctor at the hospital. This if done many times is deemed ineffective because it is time consuming and requires relatively expensive costs, therefore an early diagnosis of portable hearing loss is designed that is expected to be able to test independently independently over and over again. This tool is equipped with SD Card data storage, where the results of the data can be consulted by a doctor for further diagnosis. This tool uses an arduino uno $R 3$ control, the frequency generator uses IC XR2206. The highest error is at the frequency of $8000 \mathrm{~Hz}$ which is $0.52 \%$, but overall all systems on the device are functioning properly and the error is still within tolerance of $10 \%$. From the results of these data, this tool can be recommended for early diagnosis of hearing function.
\end{abstract}

Keywords-audiometer, sound, arduino

\section{INTRODUCTION}

Hearing is the five human senses that have the function to capture sound, so that everything that is around us can be heard. The frequency of sound that can be heard by humans ranges from $20-20 \mathrm{KHz}$. People who cannot use hearing are called deaf. Deafness has reached $16.8 \%$ of the population of Indonesia and $0.4 \%$ for deafness with the highest group at school age (7-9 years). Besides that, it is estimated that every year there will be around 5200 babies born deaf. This figure will put Indonesia, including a country that has a high deafness rate in Southeast Asia.

Research on hearing diagnosis has been widely studied by previous researchers. The application of Mathematical Modeling for the Assessment of the Risk of Developmental Delay in Young Deaf Children was studied by Mashevskiy, Sablina and Dubrovina [1]. Objective Audiometry Based on Middle Ear Parameter Formulas: A New Technique for Research and Differential Diagnosis of Hearing was investigated by Naida [2]. EVOTION - Big Data Supports Public Hearing Health Policy researched by Christensen and Pontoppidan [3]. The application of IOS-based Ear Scales for Clinical Audiology and Otology was studied by Liao [4]. Smartphone-based self-auditory assessment using phonemes was studied by Jong Min Choi [5]. The objective neurophysiological assessment of the perception of sound quality by hearing impaired listeners was studied by Millman, Stone and Tan [6].
An algorithm design for eliminating artifacts in the embedded auditory diagnostic system was investigated by Haimeng [7]. Using a Dynamic Tracking Filter to Extract the Autoacoustic Emissions of Distortion Products Induced by the Hue Signal Swept was investigated by Jun Deng [8]. Phoneme-based self-auditory assessment on smartphones was studied by Choi [9]. A comprehensive cloud-based remote hearing diagnostic system was studied by Yao [10]. Learn about self-assessment using speech sounds researched by Sohn [11]. The development of a portable A-ABR screener using a microprocessor was investigated by Hyung Wook Noh [12]. The design of a web service based system for remote hearing diagnosis was investigated by Jianchu Yao, Yongbo Wan and Givens [13].

From previous research on hearing diagnosis, it appears that the level of hearing loss (hearing threshold) in an individual can be determined by various types of hearing tests including whisper tests, fork tests, audiometric tests. Until now, the audiometer has developed into various types, including pure tone audiometer and speech audiometer. In a pure tone audiometer the hearing test system uses a digital circuit that can produce pure tones with various frequencies $(125,250 \mathrm{~Hz}, 500 \mathrm{~Hz}, 1000 \mathrm{~Hz}, 2000 \mathrm{~Hz}, 4000 \mathrm{~Hz}, 8000 \mathrm{~Hz})$ and the intensity level can be adjusted in decibels (dB). Whereas in the audiometer the hearing test system uses selected words that have been standardized, pronounced through a calibrated circuit. The audiometer has been studied by several researchers. The development of an auditory selfassessment pure tone audiometer was investigated by Gargouri, Chaoui and Wira [14]. Automatic Hearing Test Equipment Based on Active Noise Control Technology was studied by Sun, Liu and Wang [15]. The conception of Pure Tone Audiometer Application Software was studied by Gargouri, Chaoui and Kachouri [16]. The determination of the patient's hearing sensitivity using data mining techniques was studied by Elbasi, Ayanoglu and Zreikat [17]. A portable audiometer to detect hearing loss at an early stage for cancer patients was studied by Rani and Patil [18]. Audiometer controlled by brain waves was studied by Sanchez, Funes and Cosme Cisneros [19]. The design of the audiometer device with integration to multiple sources was studied by Isler and Uzun [20]. Using wireless telecommunication technology to promote tele-audiology was researched by Daoyuan Yao, Givens and Yao [21]. A comprehensive cloud-based remote hearing diagnosis system was studied by Yao [22]. The adaptive expert system for audiologists was studied by Rajkumar, Muttan and Pillai [23].

Arduino microcontroller is used to process data on the digital advanced audiometer. Arduino microcontrollers are 
widely used in sensor data processing such as Arduino-based Digital Liquid Density Meter Design [24], turbidimeter design and realization using a TSL250 photodetector and Arduino microcontroller [25], A Home Environmental Monitoring Design in Arduino [26], Water monitoring systems using arduino with labview [27], Environmental Temperature Monitoring of the Arduino Assisted Engineering Faculty using Telegram [28], Arduino UNO and GSM-based wireless health monitoring system for patients [29] and induction motor fault detection, protection and speed control using Arduino [30].

Along with age and noisy work environment factors, the function of the ear organ can sometimes be weakened unnoticed, because too often hear in high noise levels, therefore it is necessary to check ear organ function regularly. Previously to test the function of the hearing organ can be done at the ENT hospital, this is less effective because it requires a long time to do the hearing test. Therefore it is necessary to design an arduino uno R3-based audiometer that is able to diagnose the hearing organs regularly at home without having to go to the hospital. This tool is also equipped with patient data storage in the form of frequency and sound intensity $(\mathrm{dB})$. This tool is also equipped with a save button for data stored on the micro SD.

\section{METHODS}

This tool uses a frequency generator with IC XR2206, its working principle is to use an RC oscillator, where the frequency produced depends on the value of the resistor and capacitor used. Frequency generator is used in order to get a sound that varies in each frequency. So this tool is categorized as pure tone audiometer.

\section{A. System components}

The audiometer uses the Arduino Uno R3 control, the frequency generator uses the XR 2206 IC, and data storage uses an SD Card. For more details, the audiometer block diagram can be seen in Figure 1. From this figure, it can be seen that the microcontroller processes the input signal generator data.

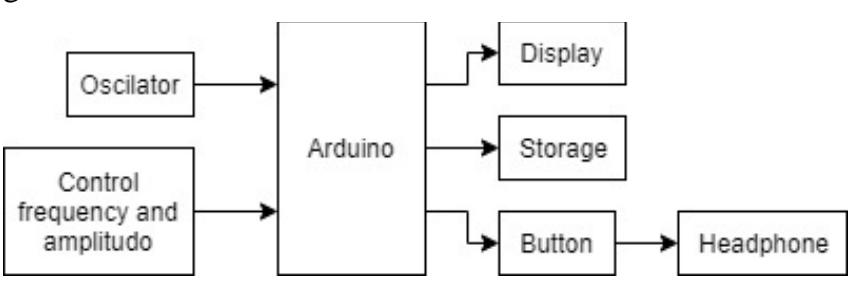

Fig. 1. System block diagram

When the on button is pressed, the supplay voltage will enter the entire circuit on the device. The oscillator will generate a frequency with a sine wave and box output. Sine waves are used to adjust the sound intensity $(\mathrm{dB})$ while square waves are used to calculate frequency values. The frequency value is set by rotating the variable resistor (potentio). The frequency will be calculated by the microcontroller by counting the number of counters per second, then displayed on the display. The sine wave will be amplified by the amplifier then connected to the headphones. Potensio is used to adjust the intensity of the sound that comes out. The sound that has come out in the form of pure tones that will be forwarded to the headphones. So that the test tone does not come out all the time, a switch is added so that the sound comes out according to the length of time required. If the patient hears, the save button will be pressed, then the $\mathrm{dB}$ and frequency displayed on the display will be stored on the SD card. Frequency and decibel values that have been tested will be stored on the micro SD in sequence based on the frequency and decibel values tested.

\section{B. Systems work flow}

When the device is turned on, LCD initialization will occur, the voltage activates the oscillator is shown in Figure 2. From the figure, Attach headphones to the patient. After that, adjust the frequency and $\mathrm{dB}$ according to the hearing test instructions according to health standards. Press the play button to make a sound. When the device starts testing see the patient's reaction, if he hears the patient will raise his hand, if the patient has heard then press the save button, do the selection of sound frequency and intensity again to do the test on the frequency and intensity of the other sounds. The process will continue to repeat until all sound frequencies and intensities have been tested. Frequency and decibel test data that can be heard by patients will be stored on micro SD with sequential save data.

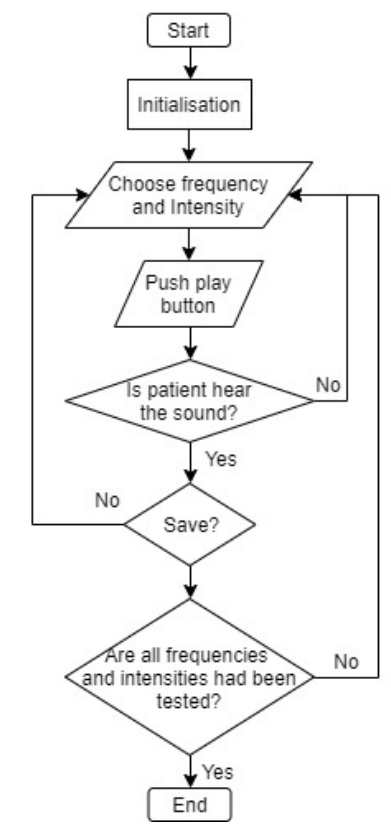

Fig. 2. System work flow diagram

\section{IMPLEMENTATION}

A tool for diagnosing hearing is shown in Figure 3. From the figure, it can be seen that there are two buttons, namely the play and save buttons. The tool also has tuning to adjust the frequency and $\mathrm{db}$.

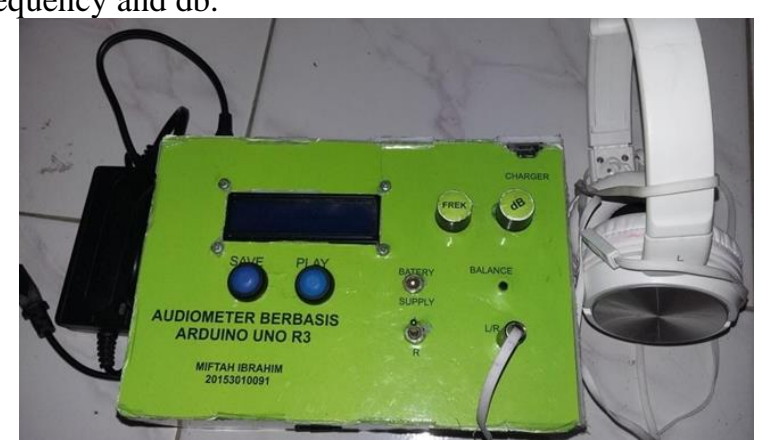

Fig. 3. Device visual 


\section{A. Frequency generator}

The function of PIN 1 is as a regulator of the amplitude of the input signal modulation is shown in Figure 4. From the figure, PIN 5 functions as an output multiplier. From the figure, the frequency produced is determined by the price of the capacitor on PIN 5.6 and the resistor on PIN 7. To adjust the output oscillation frequency, a pin is mounted on pin 7. PIN 2 as a sine wave output, then enters the voltage amplifier transistor circuit. PIN 11 as a square wave output, then it enters the amplifier transistor circuit. The inbox wave is micro to be used as a value to calculate frequency. While the sine wave will go into the amplifier circuit.

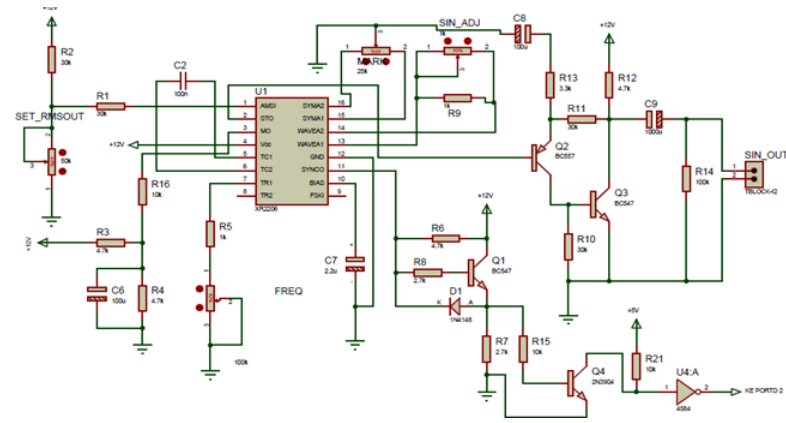

Fig. 4. Frequency generator schematic

\section{B. Amplifier}

Sine wave, entering the potentio (RV3) is shown in Figure 5. Potensio functions as a regulator of the height of the sine wave that goes to foot 3 in U1.B. After the C4 capacitor is installed which functions as a coupling, the function is to block the DC voltage from the next circuit so that it does not affect each other (Test Point 1). After the signal capacitor enters the circuit connected to PORTC 2 as ADC 2, the reference voltage is $2.5 \mathrm{~V}$. Before entering foot $3 \mathrm{U} 1 . \mathrm{B}$ the signal enters the voltage divider at R7 and R12 (Test Point 2). Potentio (RV3) is adjusted to OpAmp U1.B 5Vpp output (Test Point 3). The $5 \mathrm{Vpp}$ voltage is the result of non-inverting reinforcement with 11 times the gain of R3 100K Ohms and R4 10K Ohms. U1.A is a buffer circuit amplifying the voltage 1 time. The output is made as a bias circuit or reference voltage so that the signal output is not below the zero line. Output U1.B then enters C7, then enters the Pot vol dB. Potensio Vol dB serves to regulate the outputs of U2.A and U2.B arranged in parallel. Strengthening at U2.A and U2.B is 1.12 times with a value of $\mathrm{R} 23=\mathrm{R} 25$ which is $1.2 \mathrm{~K}$ Ohms and $\mathrm{R} 24=\mathrm{R} 28$ which is $10 \mathrm{~K}$ Ohms. The U2.A output is used as the ADC 1 input, while the U2.B output is connected to the headphones. The function of capacitor C13 is to block DC waves so that only sine waves enter the headphones.

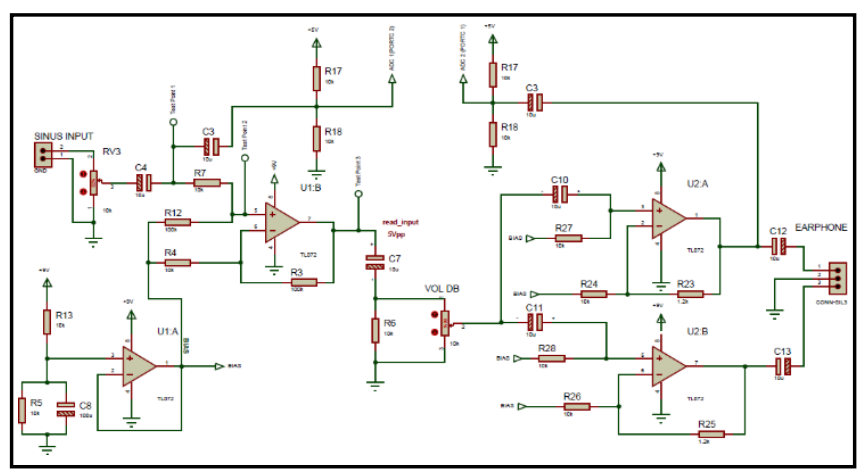

Fig. 5. Amplifier schematic
To simplify research, it is necessary to know the waveform at each test point. The following are the waveforms at each test point.

The output signal from U1.B, with an amplitude of approximately $5 \mathrm{Vpp}$. This value is the result of the strengthening of the signal test point 2 .

\section{System minimum}

The minimum system circuit in this module serves as the overall module work control is shown in Figure 6. From the figure, the function of the crystal is as an additional clock connected to the capacitor which is useful for emptying and charging the oscillator, in fact the ATMega328p already has an internal clock but the frequency is still small so it is not optimal in data processing. The 328p ATMega IC is given a program that will control the module's working system. The program used in this module uses the Arduino program.

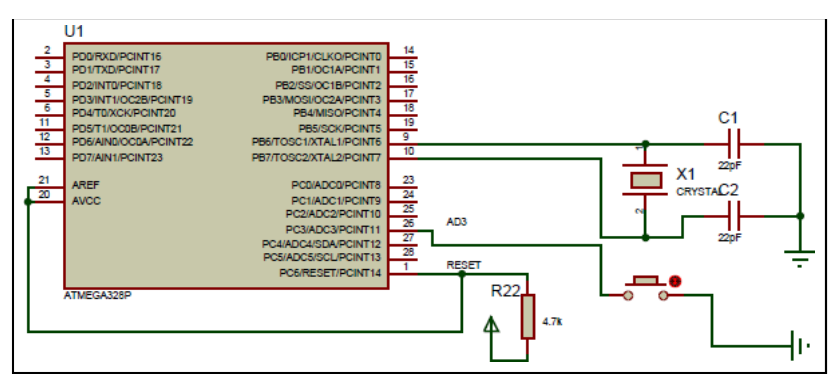

Fig. 6. System minimum schematic

Following the functions of the ports on ATMega328p, PD2 is connected to IC 4584. PD3 to PD7 plus PB0 are connected to the LCD circuit. PB2 through PB5 are connected to the SD card module. PB6 and PB7 are each connected to the crystal foot. $\mathrm{PC} 1$ as the ADC2 input, PC2 as the ADC1 input. PC3 is connected to the save button push button. PC4 is connected to SDA, PC5 is connected to SCL on the RTC 1307 module.

\section{RESULT AND DISCUSSION}

After the tool is finished, the next step is to test and measure is shown in table 1 . The purpose of testing and measuring the tool is to make sure the tool is functioning properly and how accurately the tool is made compared to the calibrated tool. The test is carried out at 7 points, namely 125 $\mathrm{Hz}, 250 \mathrm{~Hz}, 500 \mathrm{~Hz}, 1000 \mathrm{~Hz}, 2000 \mathrm{~Hz}, 4000 \mathrm{~Hz}$ and 8000 $\mathrm{Hz}$.

TABLE I. FREQUENCY MEASUREMENT RESULT

\begin{tabular}{|c|c|c|c|c|}
\hline \multirow{2}{*}{$\begin{array}{l}\text { No. } \\
\text { test }\end{array}$} & \multirow{2}{*}{$\begin{array}{c}\text { Frequency } \\
(\mathrm{Hz})\end{array}$} & \multicolumn{2}{|c|}{ Data } & \multirow[b]{2}{*}{ Error } \\
\hline & & Average (Hz) & Deviation $(\mathrm{Hz})$ & \\
\hline 1 & 125 & 124.4 & 0.6 & $0.48 \%$ \\
\hline 2 & 250 & 249.28 & 0.72 & $0.288 \%$ \\
\hline 3 & 500 & 497.4 & 2.6 & $0.52 \%$ \\
\hline 4 & 1000 & 1005.2 & 5.2 & $0.52 \%$ \\
\hline 5 & 2000 & 2013.8 & 13.8 & $0.68 \%$ \\
\hline 6 & 4000 & 3979 & 21 & $0.528 \%$ \\
\hline 7 & 8000 & 7964.2 & 36 & $0.45 \%$ \\
\hline
\end{tabular}


In Table 1 above the first test, a frequency measurement of $125 \mathrm{~Hz}$ was carried out and an average frequency of 124.4 $\mathrm{Hz}$ was obtained with an error value of $0.48 \%$. The second test was carried out at a frequency measurement of $250 \mathrm{~Hz}$ and an average frequency of $249.28 \mathrm{~Hz}$ was obtained with an error value of $0.288 \%$. The third test was carried out at a frequency measurement of $500 \mathrm{~Hz}$ and an average frequency of 497.4 was obtained with an error of $0.52 \%$. The fourth test was carried out at $1000 \mathrm{~Hz}$ frequency measurements and an average frequency of $1005.2 \mathrm{~Hz}$ was obtained with an error value of $0.52 \%$. The fifth test was carried out at $2000 \mathrm{~Hz}$ frequency measurements and an average frequency of 2013.8 $\mathrm{Hz}$ was obtained with an error value of $068 \%$. The sixth test was carried out at a frequency measurement of $4000 \mathrm{~Hz}$ and an average frequency of $3979 \mathrm{~Hz}$ was obtained with an error value of $0.528 \%$. The seventh test was carried out at a frequency measurement of $8000 \mathrm{~Hz}$ and an average frequency of $7964 \mathrm{~Hz}$ was obtained with an error value of $0.45 \%$.

\section{CONCLUSION}

After conducting all the testing and measurement processes, the following conclusions can be obtained. Arduino-based audiometer successfully made with sufficient sensitivity based on the results of the above data with a frequency error rate below 1\%. An audiometer can be made with an LCD display to display the frequency and intensity of the sound to be tested. The device is made portable so it can be used without connecting to PLN electricity. The tool is equipped with data storage of test results stored on micro SD that can be used for further diagnosis.

\section{REFERENCES}

[1] G. Mashevskiy, Y. Sablina, and P. Dubrovina, "Application of Mathematical Modeling for Assessment of Developmental Delays Risk in Young Children whith Hearing Impairments," in 2019 Ural Symposium on Biomedical Engineering, Radioelectronics and Information Technology (USBEREIT), 2019, pp. 86-89.

[2] S. Naida, V. Didkovskyi, O. Pavlenko, and N. Naida, "Objective Audiometry Based on the Formula of the Middle Ear Parameter: A New Technique for Researches and Differential Diagnosis of Hearing," in 2019 IEEE 39th International Conference on Electronics and Nanotechnology (ELNANO), 2019, pp. 425-428.

[3] J. H. Christensen and N. H. Pontoppidan, "EVOTION - Big Data Supporting Public Hearing Health Policies," in 2019 IEEE 32nd International Symposium on Computer-Based Medical Systems (CBMS), 2019, vol. 2019-June, pp. 7-8.

[4] W.-H. Liao, P.-C. Li, S. T. Young, Y.-H. Lai, and Y. Tsao, "IOS-based Ear Scale application for Clinical Audiology and Otology Usage," in 2018 11th International Symposium on Chinese Spoken Language Processing (ISCSLP), 2018, vol. 5, pp. 497-498.

[5] Jong Min Choi, Junil Sohn, Yunseo Ku, and Dongwook Kim, "Smartphone-based self hearing assessment using phonemes," in 2013 IEEE International Conference on Consumer Electronics (ICCE), 2013, vol. 2017-Janua, pp. 356-357.

[6] R. E. Millman, M. A. Stone, and C.-T. Tan, "Objective neurophysiological assessment for sound quality perception by hearing-impaired listeners," in 2017 Asia-Pacific Signal and Information Processing Association Annual Summit and Conference (APSIPA ASC), 2017, no. December, pp. 803-807.

[7] S. Haimeng, "Algorithm design of artifact removal in the embedded hearing diagnosis system," in 2015 10th International Conference on Computer Science \& Education (ICCSE), 2015, no. Iccse, pp. 651653.

[8] Jun Deng, Shixiong Chen, Xiaoping Zeng, and Guanglin Li, "Using a Dynamic Tracking Filter to Extract Distortion-Product Otoacoustic Emissions Evoked With Swept-Tone Signals," IEEE J. Biomed. Heal. Informatics, vol. 18, no. 4, pp. 1186-1195, Jul. 2014.
[9] J. M. Choi, J. Sohn, Y. Ku, D. Kim, and J. Lee, "Phoneme-based self hearing assessment on a smartphone," IEEE J. Biomed. Heal. Informatics, vol. 17, no. 3, pp. 526-529, 2013.

[10] J. Yao, D. Yao, S. Kim, and G. Givens, "A comprehensive cloud-based remote hearing diagnosis system," Proc. - IEEE Symp. Comput. Med. Syst., pp. 493-496, 2013.

[11] J. Sohn, D. Kim, Y. Ku, K. Lee, and J. Lee, "Study on self hearing assessment using speech sounds," Proc. Annu. Int. Conf. IEEE Eng. Med. Biol. Soc. EMBS, no. 1, pp. 2384-2387, 2011.

[12] Hyung Wook Noh, Tak Hyung Lee, Jong Wook Kim, Dong In Yang, Eun Jong Cha, and Deok Won Kim, "Development of a portable AABR screener using a microprocessor," in 2009 Annual International Conference of the IEEE Engineering in Medicine and Biology Society, 2009, no. c, pp. 915-918.

[13] Jianchu Yao, Yongbo Wan, and G. Givens, "Design of a web services based system for remote hearing diagnosis," in 2009 Annual International Conference of the IEEE Engineering in Medicine and Biology Society, 2009, pp. 5215-5218.

[14] M. Gargouri, M. Chaoui, and P. Wira, "Development of hearing selfassessment pure tone audiometer," in 2020 IEEE International Conference on Design \& Test of Integrated Micro \& Nano-Systems (DTS), 2020, pp. 1-5.

[15] C. Sun, Y. Liu, and X. Wang, "An Automated Hearing Test Equipment Based on Active Noise Control Technology," in 2019 IEEE International Instrumentation and Measurement Technology Conference (I2MTC), 2019, vol. 2019-May, pp. 1-5.

[16] M. Gargouri, M. Chaoui, and A. Kachouri, "Conception of a Software Pure Tone Audiometer Application," in 2018 15th International MultiConference on Systems, Signals \& Devices (SSD), 2018, pp. 619-622.

[17] E. Elbasi, D. K. Ayanoglu, and A. Zreikat, "Determination of Patient's Hearing Sensitivity using Data Mining Techniques," in 2018 IEEE 12th International Conference on Application of Information and Communication Technologies (AICT), 2018, pp. 1-6.

[18] R. Rani and H. T. Patil, "Portable audiometer for detecting hearing disorder at an early stage for cancer patient," in 2016 International Conference on Automatic Control and Dynamic Optimization Techniques (ICACDOT), 2016, pp. 119-123.

[19] G. M. C. Sanchez, F. J. G. Funes, and M. en C. I. G. Cosme Cisneros, "Audiometer controlled by brain waves," in 2016 9th International Kharkiv Symposium on Physics and Engineering of Microwaves, Millimeter and Submillimeter Waves (MSMW), 2016, no. June, pp. 14.

[20] Y. Isler and Y. O. Uzun, "Audiometer device design with integration to different sources," in 2016 Medical Technologies National Congress (TIPTEKNO), 2016, pp. 1-4.

[21] Daoyuan Yao, G. Givens, and J. Yao, "Using wireless telecommunication technology to promote tele-audiology," in 2013 Wireless Telecommunications Symposium (WTS), 2013, pp. 1-4.

[22] J. Yao, D. Yao, S. Kim, and G. Givens, "A comprehensive cloud-based remote hearing diagnosis system," in Proceedings of the 26th IEEE International Symposium on Computer-Based Medical Systems, 2013, pp. 493-496.

[23] S. Rajkumar, S. Muttan, and B. Pillai, "Adaptive expert system for audiologists," in 2011 International Conference on Communications and Signal Processing, 2011, pp. 305-309.

[24] P. Megantoro, A. Widjanarko, R. Rahim, K. Kunal, and A. Z. Arfianto, "The Design of Digital Liquid Density Meter Based on Arduino," J. Robot. Control, vol. 1, no. 1, pp. 1-6, 2020.

[25] H. Zhang, G. Li, and Y. Li, "A Home Environment Monitoring Design on Arduino," in 2018 International Conference on Intelligent Transportation, Big Data \& Smart City (ICITBS), 2018, pp. 53-56.

[26] G. Wiranto, I. D. P. Hermida, A. Fatah, and Waslaluddin, "Design and realisation of a turbidimeter using TSL250 photodetector and Arduino microcontroller," in 2016 IEEE International Conference on Semiconductor Electronics (ICSE), 2016, vol. 2016-Septe, pp. 324327.

[27] Y. K. Taru and A. Karwankar, "Water monitoring system using arduino with labview," in 2017 International Conference on Computing Methodologies and Communication (ICCMC), 2017, vol. 2018-Janua, no. Iccmc, pp. 416-419.

[28] M. W. Hariyanto, A. H. Hendrawan, and R. Ritzkal, "Monitoring the Environmental Temperature of the Arduino Assistance Engineering 
Faculty Using Telegram,” J. Robot. Control, vol. 1, no. 3, pp. 96-101, 2020.

[29] P. W. Digarse and S. L. Patil, "Arduino UNO and GSM based wireless health monitoring system for patients," in 2017 International Conference on Intelligent Computing and Control Systems (ICICCS), 2017, vol. 2018-Janua, pp. 583-588.
[30] R. Waswani, A. Pawar, M. Deore, and R. Patel, "Induction motor fault detection, protection and speed control using arduino," in 2017 International Conference on Innovations in Information, Embedded and Communication Systems (ICIIECS), 2017, vol. 2018-Janua, pp. 15 . 